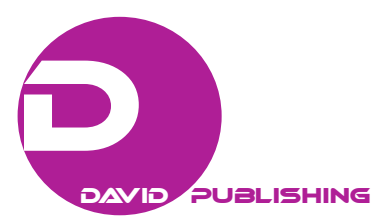

\title{
Firm Size, Innovation and Vertical Integration Incentives: The Case of Food Supply Chain
}

\author{
Amina Omrane \\ Faculté des Sciences Économiques et de Gestion de Sfax (FSEGS), Sfax, Tunisia \\ Mohamed Amine Benmehaia \\ École Nationale Supérieure d’Agronomie, Alger, Algeria
}

\begin{abstract}
This study aims to investigate and explore the relationship between vertical integration and the firm's innovativeness in food supply chain. For doing so, a two-stage least-squares model was used. It encompassed instrumental variables that attempt to describe the effective determinants of firm's vertical integration willingness. Results based on data concerning a set of 130 food-manufacturing firms, highlighted that vertical integration of a firm is strongly affected by internal incentives such as innovation rate and firm size. Moreover, it is simultaneously influenced by the economies of scale and some structure incentives. To conclude, results indicate globally that important and statistically significant differences exist across the studied firms and the small effective ones which acquire a high level of vertical integration.
\end{abstract}

Keywords: vertical integration, firm size, performance, innovation, food supply chain

\section{Introduction}

The objective of this paper is to shed some light on the determinants and consequences of firms' vertical integration in 130 Algerian manufacturing firms operating in the food supply chain. Indeed, food supply chains are becoming more and more closely integrated. However, the potential competitive effects of vertical integration are still too ambiguous in theory. Besides, a few empirical studies that were conducted in developing countries attested the controversial debate that is committed on the subject.

The dataset, which is based directly on managers' responses to survey questions, provides thorough information on firms' internal characteristics. Through some empirical measures of the firm's internal characteristics, this study is based on the hypothesis stipulating that vertical integration of food firms is strongly influenced by their size, performance, and innovativeness.

In this perspective, results showed that, on one hand, small and less innovative food firms have a great potential for vertical extending of the market. On the other hand, the innovativeness capacity of these firms has strong effects on their vertical integration willingness in the food supply chain.

Amina Omrane, Ph.D., associate researcher in ECSTRA Department, Institut des Hautes Études Commerciales (IHEC), Carthage Presidency, Tunisia; assistant professor in management science and entrepreneurship at Faculté des Sciences Économiques et de Gestion de Sfax (FSEGS), Sfax, Tunisia.

Mohamed Amine Benmehaia, Ph.D. student at Departement of Rural Economy, École Nationale Supérieure d’Agronomie, Alger, Algeria.

Correspondence concerning this article should be addressed to Amina Omrane, Road of Tunis, Km 5-5, Sakiet Ezzit, Sfax, 3021, Tunisia. 
The paper proceeds as follows: Section 2 briefly describes the conceptual framework of vertical integration food firms' determinants; section 3 gives a description of the model used in the underlying study; while section 4 exposes the empirical results; and finally, section 5 concludes.

\section{Literature Review}

In order to provide a brief summary of recent theoretical and empirical development related to vertical integration, the most recent studies on vertical integration determinants were examined. These researches were undertaken by Aghion, Griffith, and Howitt (2006), Acemoglu, Aghion, Griffith, and Zilibotti (2007), and Acemoglu, Johnson, and Mitton (2009). More specifically, Whinston (2003), Brocas (2003), and Klein (2005) have focused on vertical integration determinants by using the transaction cost theory.

The conceptual framework on the food field had conventionally operated in an open production system, relying on price signals to coordinate the activities in a production chain. However, the use of contractual production and vertical integration has expanded as a mechanism of coordination. In developed countries, it appears that the market structure is shifting from an open production towards a contracting one based on vertical integration. As a result, the food supply chains are becoming more and more closely integrated. However, the potential competitive effects of vertical integration forms are still too ambiguous in theory (Ursino, 2009). Besides, a few empirical studies that were conducted in developing countries attest the controversial debate that is committed on the subject.

More specifically, the nature of agricultural-based industries in Algeria has appealed for the awareness of the ongoing importance and need for vertical integration in practice. Many firms operating in the food supply chain are considered as small and medium enterprises. They are invited to work and cooperate closely together as small companies cannot meet the overwhelming demands of the market. Indeed, efficient vertical integration allows small and medium enterprises to be well-integrated in a supply chain.

In theory, vertical integration can be defined as the inclusion within one business firm of those activities that were previously located in two different firms involved in arm's length market transactions with each other. Thus, vertical integration can be interpreted as the substitution of the market internal organization (Coase, 1937). According to Teece (2010), the “Coasian” firm has a simple decision making calculus that supposedly determines the boundaries of the firm. Those ones are set by bringing transactions into the firms so that the marginal costs of organizing inside the firm are equilibrated with the costs associated with transactions in the market. Moreover, another key feature of the coasian firm concerns its emphasis on authority and the employment relationships as the backbones of the enterprise. Zylbersztajn and Farina (1999) argued that it is feasible to deal with the supply chain as a particular case within vertical production systems' management.

The extent of vertical integration varies from one firm to another even in the same industry. Understanding the motives and implications behind the choice of integration from its alternatives requires a well-developed theory of the firm. There is a vast literature on the determinants of vertical integration strategies and their potential impacts on profitability and dynamic performance (such as productivity, product innovation, and competitiveness). While, when reviewing the literature on vertical integration, findings with regard to performance effects are not unequivocal, as well as those related to the correlation between vertical integration and performance remain ambiguous. 
According to Frésard, Hoberg, and Phillips (2013), deciding to vertically integrate, or to be committed in vertical mergers should be related to the supply chain characteristics. In this perspective, Isaksen, Dreyer, and Grønhaug (2011) argued that vertical integration is a frequently applied strategy which is adopted in order to overcome market imperfections and thus to enhance firms’ performance. However, according to Lu and Tao (2008), the degree of vertical integration has consistently a statistically negative and significant impact on firm productivity. In another perspective, maintaining a technological control of the innovation trajectory requires sometimes a vertical integration (including heavy investment in R\&D).

In this research, three hypotheses were developed. They are related to the main determinants of vertical integration in the food supply chain: innovation, size, and performance.

\section{Innovation and Vertical Integration}

The first hypothesis corresponds to the relationship between innovation and vertical integration.

Stuckey and White (1993, p. 71) argued that

When the innovator is protected from imitators by a patent or trade secret and specific complementary assets either are not critical or are available in competitive supply, the innovator should license to all comers and price for the long run.

This strategy is generally applied in industries like petrochemicals and cosmetics, needing for easier and complementary assets to cope.

More recently, Bresnahan and Levin (2012) have advanced that the integrated upstream firm has an excessive investment incentive. They added that vertical integration enhances both upstream and downstream investment incentives, but also strengthens the foreclosure effect. In the same perspective, Lahiri and Narayanan (2013) have stipulated that vertically integrated firms benefit less than their vertically specialized counterparts in leveraging higher innovation (financial) performance with increasing alliance portfolio size.

In this context, through the nature of food industries, it seems that the less innovative firms are the most vertically integrated (Karantininis, Sauer, \& Furtan, 2010). For this reason, the first hypothesis will be as follows:

Hypothesis 1: The food industry firm's innovativeness has a negative effect on the firm's extent in the market.

\section{Vertical Integration and Firm Size}

The second hypothesis claims that the firm size is a determinant of its whole internal characteristics. Even if Wengel and Shapira (2004) have pointed out that there is no "clear-cut" relationship between vertical integration and size. Acemoglu, Griffith, Aghion, and Zilibotti (2010) considered that small and medium enterprises are more innovative, and then, more vertically integrated.

According to Kilmer (1986) as well as Lahiri and Narayanan (2013), the firm size is the main determinant of a firm's behavior and its vertical integration capacity. Therefore, the second hypothesis could be developed as follows:

Hypothesis 2: Small and medium companies present a high potential of vertical integration.

\section{Vertical Integration and Performance}

The third hypothesis advances that there is a positive relationship between vertical integration and performance. Indeed, Forbes and Lederman (2010) have investigated performance implications of a firm's 
vertical integration in the airline industry (shorter delays and fewer cancellations). However, another study undertaken by $\mathrm{Lu}$ and Tao (2008) has proved that the degree of vertical integration has a negative and a statistically significant impact on productivity.

Lafontaine and Slade (2007) have examined the consequences of firm vertical boundary across a range of industries. This was due to the fact that the impacts of vertical integration on firm performance are generally industry-specific. These effects vary also according to the type of service offered by the company. In the same perspective, Roder (2007) provided evidence that the extent of vertical integration is positively correlated with firm performance and that it is specifically related to share price performance of six of the world's largest media conglomeration in the USA and Europe.

Then, it is argued that vertical integration strategy depends on the firm's performance (Forbes \& Lederman, 2010).

The following hypothesis could be proposed below:

Hypothesis 3: The extent of vertical integration of a food industry firm is positively correlated with its performance.

\section{Research Methods}

The authors used a two-stage least squares model with instrumental variables that attempt to estimate the effective determinants of a firm's vertical integration willingness.

$$
Y=\beta_{1}+\beta_{2} X_{1}+\beta_{3} X_{2}+\varepsilon_{i}
$$

The dependant variable $Y$ is a measure of the firm's vertical integration. They adopt a classical measure index of the ratio of the added value on the sales. The first use of this measurement is by Adelman (1955). When comparing it to other measurements applied in the literature, the most obvious and reasonable counterpart would be the "value added over sales" (VA/S) measure. So, by denoting $s_{i}(i=1, \ldots, 130)$ as the firm's sales, and $\mathrm{VA}_{i}$ the firm's value added, $Y$ is obtained such as :

$$
Y=\mathrm{VA}_{i} / s_{i}
$$

More specifically, $X_{1}$ reflects the independent variables such as: firm size, performance, and innovativeness. Besides, $X_{2}$ reflects the instrumental variables used in addition to CEO size, total employees, and the productivity of the firm.

The measures of the independent variables are developed as follows: The firm size is calculated by the percentage of sales in the whole supply chain. By denoting $S$, the total sales value in food supply chain, the firm size (FS) is presented in this way:

$$
\mathrm{FS}=s_{i} / S
$$

The firm's performance is based on a financial ratio of assets' returns. By denoting the $r_{i}$ as the firm's net return, and $A_{i}$ as the total assets of the firm, the firm's performance ratio (PER) becomes like so:

$$
\mathrm{PER}=r_{i} / A_{i}
$$

The firm's innovativeness is measured by a ratio, where $P_{0}$ and $P_{t}$ are respectively the initial and the actual innovated products. The innovation rate (IN) is then derived like so:

$$
\mathrm{IN}=\left(P_{0}+P_{t}\right) / \mathrm{AGE}
$$


As a continuous variable, the innovation rate reflects the ability of the firm to precede innovations in time. The firm age is measured by its years of activity. This leads to the fact that the innovation rate reveals the number of firm product-line innovations per year. Concerning the instrumental variables, they are measured as follows: The number of CEO members approaches the CEO size and the total employees' number is an affectation of the number of permanent employees in the firm. Finally, the productivity of the firm is measured by the ratio of the firm's added value on the firm's total employees' number.

\section{Results and Discussion}

The main empirical results will be presented through the analysis of models emanating from the selected data. The robustness and effectiveness of the modeling developed are demonstrated and the colinearity diagnosis exposes no difficulties. First of all, some descriptive statistics of the sample will be presented in the Table 1 below.

Table 1

Summary Statistics for 130 Observations

\begin{tabular}{lllll}
\hline Variables & Mean & Min & Max & Std. Dev. \\
\hline Vertical integration & 0.381 & 0.059 & 0.890 & 0.147 \\
Firm size & 0.769 & 0.001 & 7.457 & 1.312 \\
Asset returns ratio & 12.906 & 0.053 & 57.204 & 10.437 \\
Innovation rate & 1.521 & 0.200 & 5.153 & 1.297 \\
CEO size & 1.407 & 0.000 & 8.000 & 2.566 \\
Employee & 150,900 & 11,000 & 758,000 & 184,902 \\
Productivity ratio & 0.770 & 0.000 & 5.340 & 1.140 \\
Ownership concentration & 45.669 & 1.600 & 100.000 & 34.208 \\
Managerial ownership & 0.184 & 0.000 & 1.000 & 0.389 \\
Firm age & 18.469 & 3.000 & 162.000 & 27.790
\end{tabular}

It shows that the mean of vertical integration measure in the food supply chain is 0.38 (with a standard deviation of 0.147). Besides, the maximum value is 0.98 which means that high differences exist in terms of vertically integrated firms. In terms of firm size, the food supply chain contains the maximum firm size at $7.45 \%$ in the market.

The firm's performance seems to be dispersed on the sample (the standard deviation value is 10.43). Concerning the innovativeness level, the more innovative firm seems to have a ratio of five innovations per year as a maximum value in the context. The sample contains different ages varying from three years to very old firms corresponding to large corporations. The description of the main other variables reflects the internal characteristics of the studied firms.

In order to estimate the firm's determinants extent in terms of vertical integration, the relationship among vertical integration, size, innovation, and performance, was checked. For beginning, the authors should confirm the endogeneity of all independent variables.

Table 2 shows the effective endogeneity of six variables with a strong statistic significance required for the two-stage least squares (TSLS) model. 
Table 2

OLS for Dependent Variable: Vertical Integration, Using 130 Observations (Heteroskedasticity-Robust Standard Errors)

\begin{tabular}{llll}
\hline Variables & Coefficient & Std. Error & $t$-ratio \\
\hline Const. & 0.318 & 0.024 & $13.139 * * *$ \\
Innovation rate & -0.031 & 0.006 & $-4.830^{* * *}$ \\
Ceo size & 0.012 & 0.004 & $3.059^{* * *}$ \\
Firm size & -0.048 & 0.009 & $-5.282^{* * *}$ \\
Employee & 0.0002 & 0.0006 & $3.399^{* * *}$ \\
Asset returns ratio & 0.005 & 0.001 & $4.216^{* * *}$ \\
Productivity ratio & 0.0006 & 0.0001 & $3.575^{* * *}$ \\
\hline
\end{tabular}

Notes. Adjusted $R$-squared = 0.259; $F(6.123)=12.311(0.0000)$; Log-likelihood = 87.643; Akaike Criterion = -161.286.

The OLS model presented in Table 2 shows a high overall significance of $F$-statistics and relative adjusted $R$-squared independencies (0.25). The firm size and innovativeness have strong negative effects on vertical integration; while the other variables have positive impacts.

The second step of modeling consists in applying a TSLS model with instrumental variables. Six instruments were chosen and three maintained as independent variables (firm size, performance, and innovativeness).

Results are represented in Table 3 as follows:

Table 3

TSLS, for Dependent Variable: Vertical Integration, Using 130 Observations, With Six Instruments (Heteroskedasticity-Robust Standard Errors)

\begin{tabular}{llll}
\hline Variables & Coefficient & Std. Error & $z$ \\
\hline Const. & 0.364 & 0.025 & $14.511^{* * *}$ \\
Firm size & -0.016 & 0.009 & $-1.696^{*}$ \\
Asset returns ratio & 0.005 & 0.001 & $3.953^{* * *}$ \\
Innovation rate & -0.026 & 0.008 & $-3.285^{* * *}$ \\
\hline
\end{tabular}

Notes. Adjusted $R$-squared = 0.136; $F(3.126)=7.807$ (0.00008); Log-likelihood = 76.068; Akaike Criterion = 144.137.

Table 3 is a TSLS, for vertical integration, as a dependant variable using 130 observations with six instruments (where the modeling uses heteroskedasticity-robust standard errors). This point confirms the fact that firm size and innovativeness have maintained their negative effects on the firm's vertical integration, whereas the firm's performance had affected positively the vertical integration level. In a part, when the vertical integration measure is simulated with the fitted one in the obtained model, a strong clear positive effect was obtained. It is shown in Figure 1.

The static forecasted value of the vertical integration measure seems to have a restricted variation area compared with effective used data values. The second graph plots the observation sorted by vertical integration measure with the forecast value in the model, which presents 130 , forecast range and lower confidence intervals. In another part, the negative effect of the innovativeness on vertical integration can be shown by plotting the fitted vs. actual values of measures. The results are shown in Figure 2. 

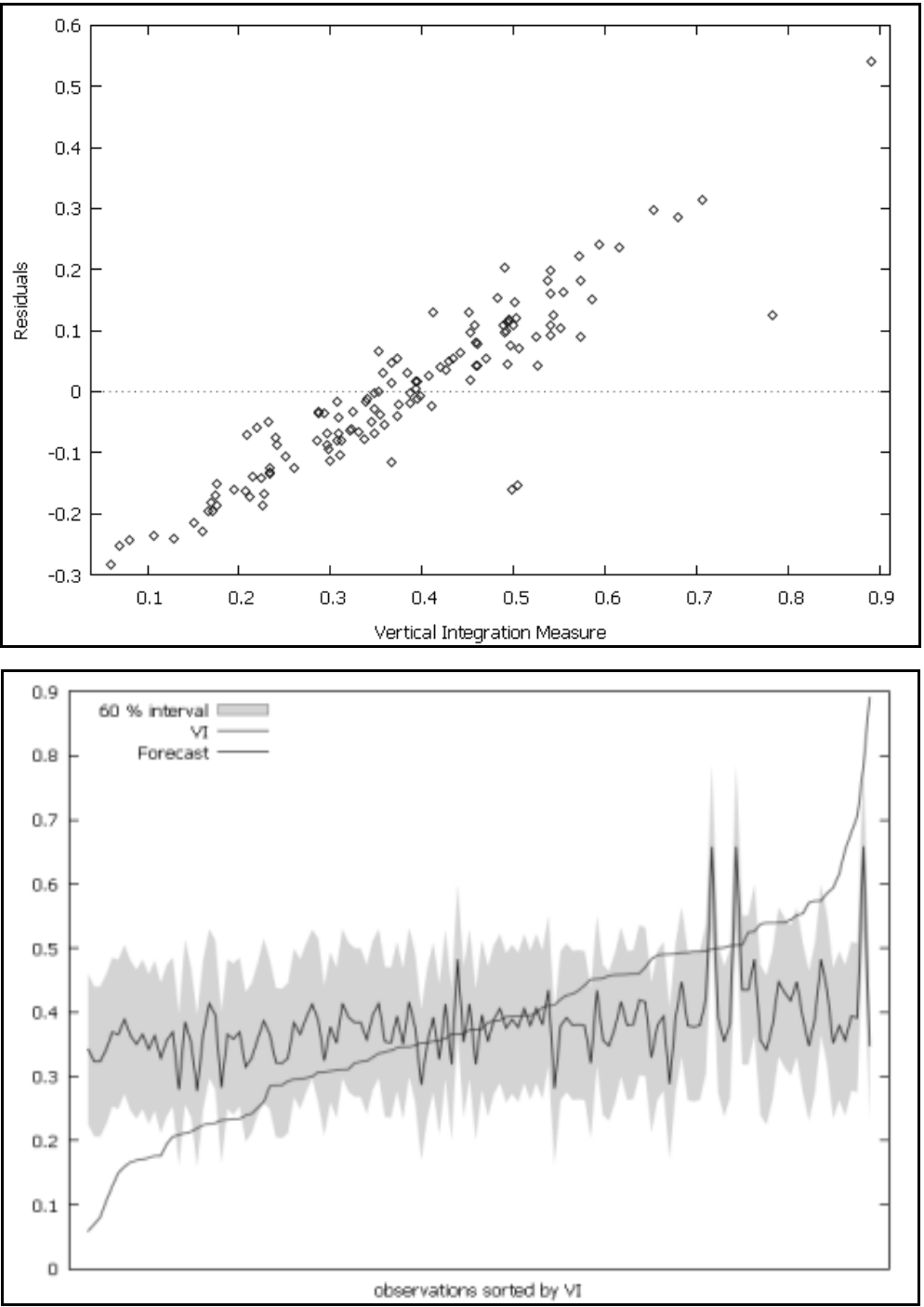

Figure 1. Vertical integration measures function to regression residuals and the forecast value.

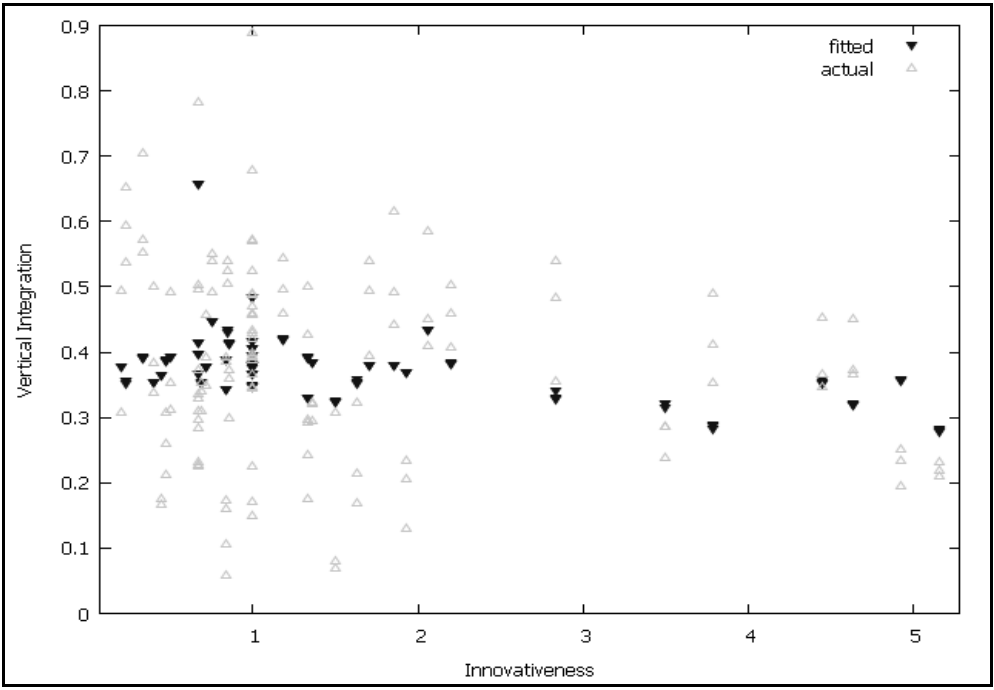

Figure 2. The fitted and actual effects of vertical integration and innovation measures. 
Similarly, the fitted and actual effects of vertical integration measures on firm size and performance were plotted like it appears in Figures 3 and 4.

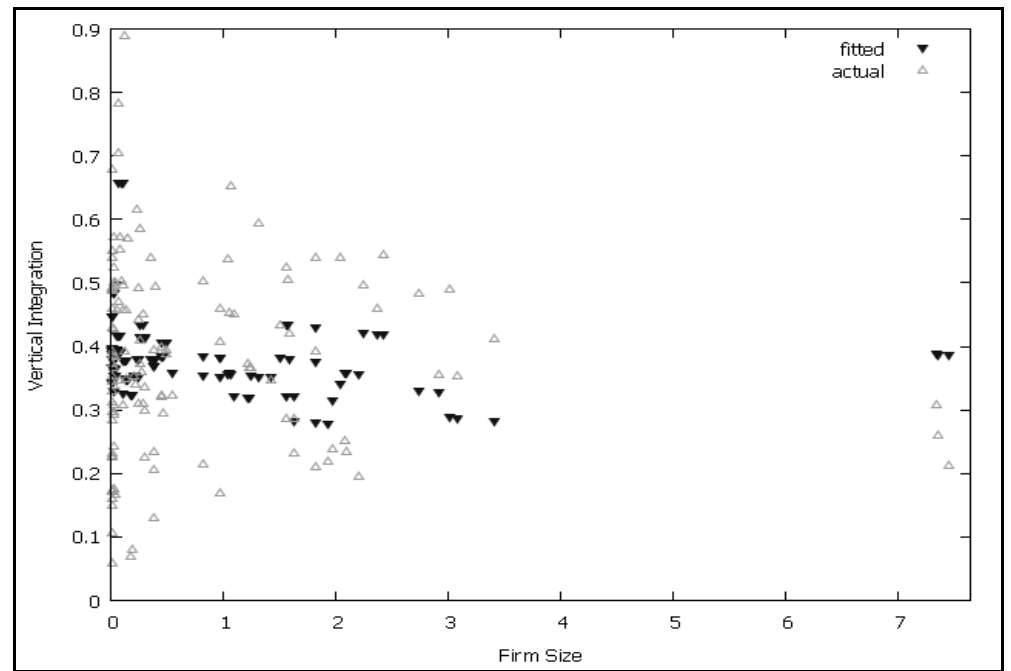

Figure 3. The fitted and actual effects of vertical integration and asset return measures.

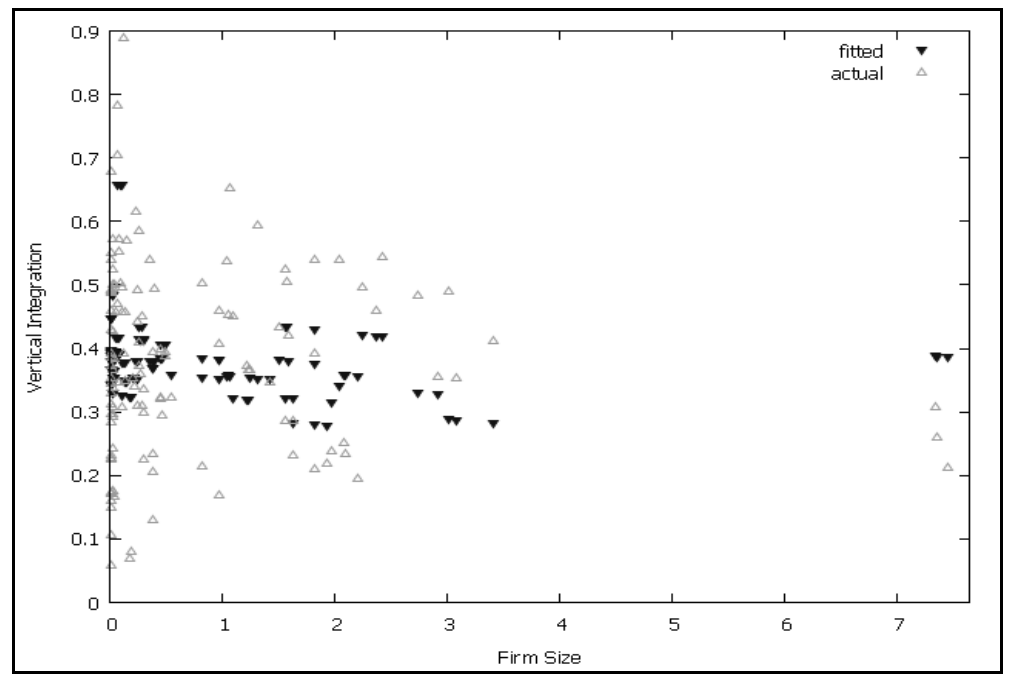

Figure 4. The fitted and actual effects of vertical integration and firm size measures.

It appears that the predicted sign is consistent with the observations' tendency. Finally, it could be asserted that, by eliminating some effects of internal characteristic differences between firms, vertical integration ability requires a higher level of performance. Indeed, small and less innovative food firms have a great potential for vertical extension of the market. These results seem to be consistent with the advanced hypothesis and corroborated by the conceptual framework presented in the study.

\section{Conclusions}

In the present study, preliminary evidence on the relationship between vertical integration and internal firms' characteristics was provided in the food supply chain. It seems that the economies of scale as well as innovativeness have strong effects on the firm's vertical extent on the market. More specifically, it was found, on one hand, that profitability has a positive effect on the firm's vertical integration. On the other hand, it was 
inferred that the small and less innovative firms present a higher potential of vertical integration. The results seem to be more consistent with the conceptual framework based on the basic theories of industrial organization. These empirical proposals provide some insights on the determinants of vertical integration in the Algerian food supply chains.

\section{References}

Acemoglu, D., Aghion, P., Griffith, R., \& Zilibotti, F. (2007). Vertical integration and technology: Theory and evidence (Institute for Empirical Research in Economics, working paper, 342).

Acemoglu, D., Griffith, R., Aghion, P., \& Zilibotti, F. (2010). Vertical integration and technology: Theory and evidence. Journal of the European Economic Association, 8(5), 989-1033.

Acemoglu, D., Johnson, S., \& Mitton, T. (2009). Determinants of vertical integration: Financial development and contracting costs. The Journal of Finance, 64(3), 1251-1290.

Adelman, M. A. (1955). Concept and statistical measurement of vertical integration. In G. J. Stigler (Ed.), Business concentration and price policy (pp. 281-330). Princeton: Princeton University Press.

Aghion, P., Griffith, R., \& Howitt, P. (2006). U-shaped relationship between vertical integration and competition: Theory and evidence. International Journal of Economic Theory, 2(3-4), 351-363.

Bresnahan, T. F., \& Levin, J. D. (2012). Vertical integration and market structure (National Bureau of Economic Research, No. w17889).

Brocas, I. (2003). Vertical integration and incentives to innovate. International Journal of Industrial Organization, 21(4), 457-488.

Coase, R. H. (1937). The nature of the firm. Economica, 4(16), 386-405.

Forbes, S. J., \& Lederman, M. (2010). Does vertical integration affect firm performance? The RAND Journal of Economics, 41(4), 765-790.

Frésard, L., Hoberg, G., \& Phillips, G. (2013). The incentives for vertical mergers and vertical integration. Research Policy, 2, 452-466.

Isaksen, J. R., Dreyer, B., \& Grønhaug, K. (2011). Vertical integration and performance: The impact of measurements and industry. Økonomisk Fiskeriforskning, 21(1), 41-59.

Karantininis, K., Sauer, J., \& Furtan, W. H. (2010). Innovation and integration in the agri-food industry. Food Policy, 35(2), $112-120$.

Kilmer, R. L. (1986). Vertical integration in agricultural and food marketing. American Journal of Agricultural Economics, 68(5), $1155-1160$.

Klein, P. G. (2008). The make-or-buy decisions: Lessons from empirical studies. In C. Ménard and M. Shirley (Eds.), Handbook of new institutional economics (pp. 435-464). Berlin: Springer-Verlag.

Lafontaine, F., \& Slade, M. (2007). Vertical integration and firm boundaries: The evidence. Journal of Economic Literature, 45(3), 629-685.

Lahiri, N., \& Narayanan, S. (2013). Vertical integration, innovation, and alliance portfolio size: Implications for firm performance. Strategic Management Journal, 34(9), 1042-1064.

Lu, Y., \& Tao, Z. (2008). Vertical integration and firm performance. Retrieved from http://papers.ssrn.com/sol3/papers. cfm?abstract_id=1222484

Roder, F. (2007). Strategic benefits and risks of vertical integration in international media conglomerates and their effect on firm performance (University of St.Gallen, Dissertation No. 3402, Difo-Druck Bamberg).

Stuckey, J., \& White, D. (1993). When and when not to vertically integrate. Sloan Management Review, $34(3), 71$.

Teece, D. J. (2010). Technological innovation and the theory of the firm: The role of enterprise-level knowledge, complementarities, and (dynamic) capabilities. Handbook of the Economics of Innovation, 1, 679-730.

Ursino, G. (2009). Supply chain control: A theory of vertical integration (Università cattolica del Sacro Cuore).

Wengel, J., \& Shapira, P. (2004). Machine tools: The remaking of a traditional sectoral innovation system. In F. Malerba (Ed.), Sectoral systems of innovation. Cambridge: Cambridge University Press.

Whinston, M. D. (2003). On the transaction cost determinants of vertical integration. Journal of Law, Economics, and Organization, 19(1), 1-23.

Zylbersztajn, D., \& Farina, E. M. (1999). Strictly coordinated food-systems: Exploring the limits of the coasian firm. The International Food and Agribusiness Management Review, 2(2), 249-265. 